\title{
ULYSSES: JOYCE AO PÉ DAS LETRAS
}

\author{
Nenhum problema tão consubstancial com as letras \\ e seu modesto mistério como o que propõe uma tradução. \\ Jorge Luis Borges
}

\section{Paulo Roberto Medeiros}

Mantendo a apreciação pelo trabalho de tradução de Ulysses, de James Joyce, elaborada pelo impecável filólogo Antônio Hoauiss, contaríamos, no entanto, com seu elevado valor intelectual para nos acompanhar em outras possíveis leituras, e, acreditamos, manter-se-ia a elas atento, como esperamos daqueles que julgamos saberem unir a ética à estética. Assim, crendo que o próprio Houaiss acolheria nossos comentários, ousamos acompanhar sua tradução acentuando algumas possíveis diferenças em alguns momentos do texto. Na verdade, em vários momentos. Dessa forma, essa é a proposição deste escrito, sendo, por enquanto, selecionadas somente algumas passagens, seguindo o propósito de se ler o referido texto ao pé-das-letras em seus múltiplos sentidos, evitando-se uma denominada leitura "livre", acentuando estar a definição de cada palavra nas letras por elas formada numa língua cuja estrutura léxica e sintática torna-se mais flexível na escrita do nosso autor, quando as palavras podem estar sempre se transformando.

Entendemos ser uma tradução "livre" um outro texto, o do tradutor; daí pretendermos buscar a leitura do texto do próprio Joyce, mesmo implicando os riscos inerentes, tanto quanto numa tradução "livre" ou de qualquer natureza, assim como os riscos implicados na própria leitura, a qual, certamente, será sempre distinta da intenção da escrita do autor.

Uma primeira constatação é a de se poder afirmar, até o momento, não haver no texto de Joyce vocábulos não dicionarizados em inglês ou em outras línguas citadas, existindo algum correlato em nossa língua. Há, sim, composição de palavras aglutinadas, mas, em sendo decompostas, encontra-se cada uma delas no uso corrente da 
língua inglesa. Às vezes Antônio Houaiss ameniza alguns termos considerados por ele - quem sabe? - um pouco mais rudes, mas que fazem parte do cotidiano; por vezes emprega termos tão sofisticados e distantes do uso corrente, tornando a passagem ininteligível; há ainda uma impressão de excesso de pudor frente ao uso de algum termo mais chulo ou quando alusivo a sexo e a palavrões, quase sempre metaforizado ou metonimizado sutilmente em Joyce, mas perdido na referida tradução.

Uma outra constatação possível é a que poderíamos denominar precisão descritiva detalhada do cotidiano, das coisas, dos objetos, palpáveis ou visuais, mantido todo o experimento da escrita na materialidade máxima da letra enquanto suporte a todas as impressões dos sentidos. Não somente o olhar e o tato, mas o olfato, o paladar e, parece-nos, sobretudo a audição buscam encontrar materialidade nas letras, quando os recursos da capacidade onomatopaica, por exemplo, são levados às últimas consequiências, numa situação em que os sons, não sabemos se passam a ser imitados pelas palavras ou se as letras os imitam.

Não há proposições metafísicas ou aforismos conclusivos como os há em Guimarães Rosa, por exemplo. Ao contrário, não há épico de cunho heróico, e sim o mais trivial de uma caminhada perambulante pela cidade num único dia, como se toda história universal da humanidade pudesse ser condensada num único dia numa vida, na vida de alguém numa cidade, Dublin, no caso, a cidade de Joyce, pois o texto é particularmente autobiográfico. Mas, apesar de todo o cenário do cotidiano surgir detalhadamente nos seus aspectos mais triviais, trata-se de um cotidiano marcado pela morte e pelo enterro desse morto, tornando-o diferente. Para além disso, o pretendido é atingir a helenização daquela polis, para, por esse meio, permear e inserir o cotidiano pelo simbólico da Cultura, indicando-nos haver a singularidade do sujeito na linguagem que lhe é própria, a particularidade contingente das línguas que fornecem os elementos de sua linguagem, e o universal possível de sua leitura no simbólico da Cultura.

Pode-se considerar ainda que o decorrer da leitura é marcado pela impressão de que o autor manteve intencionalmente a multiplicidade de sentidos na escrita usando o método de aplicar a simultaneidade, aglutinando, condensando numa única palavra, frase ou período várias possibilidades viabilizadas na sucessividade 
polifônica da narrativa inevitável decorrente da leitura, do mesmo modo como as ocorrências nos sonhos e sua narrativa. Assim, ao se ler o texto, sobretudo quando em voz alta e em inglês, há uma explosão de múltiplas possibilidades através de uma polifonia homofônica sempre inusitada a gerar múltiplos sentidos, resultado de uma polissemia abundante. Para usar de uma analogia propiciada por nossos festejos juninos, há palavras em Joyce parecidas com a imagem de um rojão que ao explodir nas alturas multiplica-se pluriformemente em sua luminescência, compondo, enfim, uma miríade possível. Há também a colaboração de regionalismos e gírias, originárias das conversações cotidianas, recebendo empregos com ampla liberdade de criação, sendo as palavras recriadas como que degustadas pelo sabor do cômico, do humor e da ironia. Há alegria no texto, como o próprio prefixo do nome do autor, Joy, prevalecendo o humor. Trata-se de um texto alegre.

Assim, levando-se em consideração tais aspectos, podemos compor alguma idéia do que seja ler a obra de James Joyce.

Para exemplificar o tratamento dado à tradução, levando-se em consideração os fatores apontados, comentemos uma passagem proposta como sendo passível de outras possíveis leituras, por considerarmos ser suficiente para indicar o que pode ser feito em todo o livro. Não estaremos também procedendo a uma exegese do texto, no sentido de pesquisar a etimologia, cada nome próprio indicado ou mesmo o contexto histórico e narrativo, mas nos deteremos literalmente na tradução, mesmo dando-nos conta daquilo que poderia ser um outro trabalho, o de cascavilhar os dados autobiográficos, se considerarmos todos os seus escritos sob tal perspectiva.

CLEVER, VERY

BRILHANTE, MUITO

James Joyce

- Clever, Lenehan said. Very.

- Gave it to them on a hot plate, Myles Crawford said, the whole bloody history.

Nightmare from which you will never awake.

\section{Antônio Houaiss}

- Brilhante - disse Lenehan -

- Serviu-lhes em prato quente Myles Crawford disse -, toda a danada da história.

Pesadelo de que jamais despertarás. 
- I saw it, the editor said proudly. I was present, Dick Adams, the besthearted bloody Corkman the Lord ever put the breath of life in, and myself.

Lenehan bowed to a shape of air, announcing:

- Madam, I'm Adam. And Able was I ere I saw Elba.

- History! Myles Crawford cried. The Old Woman of Prince's street was there first. There was weeping and gnashing of teeth over that. Out of an advertisement. Gregor Grey made the design for it. That gave him the leg up. Then Paddy Hooper worked Tay Pay who took him on to the Star. Now he's got in with Blumenfeld. That's press. That's talent. Pyatt! He was all their daddies.

- The father of scare journalism, Lenehan confirmed, and the brotherin-law of Chris Callinan.

- Hello?... Are you there?... Yes, he's here still. Come across yourself.

- Where do you find a pressman like that now, eh? The editor cried.

He flung the pages down.

- Clamn dever, Lenehan said to Mr O'Madden Burke.

- Very smart, Mr O'Madden Burke said.

Professor MacHugh came from the inner office.

- Talking about the invincibles, he said, did you see that some hawkes

- Eu o vi - disse orgulhosamente o diretor. - Eu estava presente, Dick Adams, o danado do filho de Cork do melhor coração a que o Senhor tenha insuflado o alento da vida, e eu próprio.

Lenehan saudou uma forma invisível, aunciando:

-Madame, oro e'm Adam. Abel met'em Leba.

- História! - clamou Myles Crawford. - A velhota da rua Prince estava lá antes. Houve lamúrias e rilhar de dentes quanto a isso. Por causa de um anúncio. Gregor Grey foi quem fez o desenho dele. Isso lhe deu uma mãozinha. Então Paddy Hooper trabalhou o Tay Pay, que o levou para o Star. Agora está com Blumenfeld. Isso é a imprensa. Isso é talento. Pyatt! Êsse é o pai de todos eles.

- O pai da imprensa amarela confirmava Lenehan, - e o cunhado de Chris Callinan.

- Alô?... Você está aí?... Sim, êle ainda está aqui. Venha então você.

- Onde é que se vai encontrar um jornalista como esse hoje em dia? Hem? - gritava o diretor.

Estralejou soltando-as as páginas.

- Banadamente drilhante - dizia Lenehan ao senhor O'Madden Burke.

- Astutíssimo - dizia o senhor O'Madden Burke.

O professor MacHugh vinha do escritório dos fundos.

- Falando dos invencíveis - disse -, viram que alguns camelôs foram 
were up before the recorder...

- O yes, J.J. O'Molloy said eagerly. Lady Dudley was walking home through the park to see all the trees that were blown down by that cyclone last year and thought she'd buy a view of Dublin. And it turned out to be a commemoration postcard of Joe Brady or Number One or Skin-the-goat. Right outside the viceregal lodge, imagine!

- They're only in the hook and eye department, Myles Crawford said. Psha! Press and the bar! Where have you a man now at the bar like those fellows, like Whiteside, like Issac Butt, like silvertongued O'Hagan? Eh? Ah, bloody nonsense! Only in the halfpenny place!

- His mouth continued to twitch unspeaking in nervous curls of disdain.

Would anyone wish that mouth for her kiss? How do yoy know? Why did you write it then?

\section{RHYMES AND REASONS}

Mouth, south. Is the mouth south someway? Or the south a mouth? Must be some. South, pout, out, shout, drouth. Rhymes: two men dressed the same, looking the same, two by two.

la tua pace che parlar ti piace .mentrechè il vento, come fa, si tace. levados para a polícia?...

- É sim - disse animoso J.J. O'Molloy. - Lady Dudley estava voltando para casa pelo parque, vendo as árvores que haviam sido derrubadas pelo ciclone do ano passado, e pensou em comprar algumas vistas de Dublin. E aconteceu que os postais comemorativos eram de Joe Brady ou do Número Um ou do Pele-deBode. Logo em frente dos alojamentos vice-reais, imaginem!

- Hoje são da turma do deixa disso - disse Myles Crawford. - Bolas! Foro e jornalismo! Onde é que no foro se pode encontrar homens daquele porte, como Whiteside, como Isaac Butt, como o O'Hagan língua-de-prata? Hem? Ah, é o lerolero de droga! Todos de circo de cavalinhos!

- Sua boca continuava crispandose insonora em contrações de desprezo.

Quereria alguém aquele boca para o seu, dela, beijo? Que sabes tu? Por que o escreveste então?

\section{RIMAS E RAZÕES}

Bôca, touca. É bôca touca de algum modo? Ou a touca uma bôca? Deve haver algo. Touca, ôca, louca, pouca, sopa. Rimas: dois homens de iguais trajes, parecendo o mesmo, dois a dois.

la tua pace che parlar ti piace .mentrechè il vento, come fa, si tace. 
He saw them three by three, Êle as viu três a três, garotas approching girls, in green, in rose, in apropinquantes, de verde, de rosa, de russet, entwining, per l'aer perso in fulvo, enlaçadas, per l'aer perso de mauve, in purple, quella pacifica malva, de púrpura, quella pacifica oriafiamma, in gold of oriflamme, di oriafiamma, de ouro de auriflama, di rimirar fe piu ardenti. But I old men, rimirar fé piu ardenti. Mas eu, penitent, leadenfooted, underdarkneath homens velhos, penitentes, the night: mouth south: tomb womb. plumbicalçados, suobscurinfra a noite: boca touca: entre ventre.

- Speak up for yourself, $\mathrm{Mr}$ - Fale por você mesmo - disse o O'Madden Burke said. senhor O'Madden Burke.

Comecemos destacando no texto supracitado:

- Madam, I'm Adam. And Able was I ere I saw Elba., assim traduzido por Houaiss:

- Madame, oro e'm Adam. Abel metem Leba.

Porém, permitindo-nos repensar a frase, obteremos outras versões possíveis, até porque a tradução proposta pelo tradutor as oculta.

Uma primeira consideração:

- Madam, I'm Adam., pode ser simplesmente:

- Madame, eu sou Adão., variações:

Havendo, no entanto, uma homofonia permitindo algumas

- Madame, eu sou uma dama [a dame], ou:

uma mãe [a dam], ou ainda:

um açudeluma represa [a dam], e:

represado/tapado [I am dam].,

Ou ainda:

- Madame, eu sou danado. [a damned], no sentido do daimon, sugerindo pelo menos mais uma possibilidade, parônima (?):

- Louco sou [Mad am], um danado. 
Mas como sempre há alguma referência concreta, a frase parece jogar com o nome antes citado, Dick Adams, objeto-alvo do martelar incessante de Joyce sobre personagens reconhecíveis.

A segunda frase do mesmo período: And Able was I ere I saw Elba joga com um termo composto pelas mesmas letras, um palíndromo (?): a b l e - e l b a, sugerindo, pelo contexto, poder ser abel, Abel. A tradução poderia ser também: E Abel eu eralestava onde vi Elba. E apto estava onde via Abel.

A seguir: History! Myles Crawford cried. História! - clamou Myles Crawford. The Old Woman of Prince's street was there first.There was weeping and gnashing of teeth over that. A Mulher Primeva do Príncipe das Trevas estava lá primeiro, havendo choro e ranger de dentes por toda parte.

Assim, através da referência a alguma conhecida velhota da rua Prince somos lançados nos primórdios da história do Gênesis frente à representante do Príncipe das Trevas, no Inferno, onde estava Eva, a Antiga Mulher. O Inferno aparecerá na manchete seguinte.

Continuando no mesmo parágrafo: Por causa de um anúncio, traduz Houaiss Out of an advertisement, que poderia ser também devido a um ankíncio, no sentido de advertência, colocado no Edem pelo Criador, não somente desenhado por Gregor Grey, como tradução de Houaiss, mas poderia também ser: $O$ Ancião Purgativo ou Gregoriano, Gregor Grey, made the design for it, assim o determinou, assim designou para ele/ela, Adão e/ou Eva, num contexto em que está a se falar do pai de todos, He was all their daddies, em relação ao talento jornalístico de Paddy Hooper referido ali numa redação de jornal. Paddy é a abreviatura de Patrick, o santo patrono da Irlanda.

Saltemos o restante de CLEVER, VERY, e passemos ao seguinte, RHYMES AND REASONS:

Bôca, touca. É bôca touca de algum modo? Ou a touca uma bôca? Deve haver algo. Touca, oca, louca, pouca, sopa. Rimas: dois homens de iguais trajes, parecendo o mesmo, dois a dois, - traduz Houaiss.

A intenção do nosso Houaiss parece haver sido a de manter a rima, conforme proposição da manchete Rimas e Razões. Mas nessa rima perde-se todo um possível sentido outro. 
Literalmente traduzido, podemos encontrar no trecho alusões aos genitais femininos:

Mouth, south. Boca, sul.

Is the mouth south someway? Há alguma boca peculiar ao sul? É a boca sul alguma via?

Or the south a mouth? Ou o sul uma boca?

Must be some. Deve haver alguma.

South, pout, out, shout, drouth. Sul, beiço espichado/amuado, espaço aberto, aclama secura/aridez/falta de chuva, de irrigação.

Rhymes: two men dressed the same, looking the same, two by two. Rimas: dois homens de iguais trajes, parecendo o mesmo, dois a dois.

A frase seguinte, sem objeções.

A seguir, citação do Inferno, de Dante, Canto 5, em italiano. la tua pace che parlar ti piace mentrechè il vento, como fa, si tace.

Os homens, dois a dois; as garotas se aproximando, três a três, He saw them three, approaching girls: in green, de verde, in rose, de rosa, in russet, de avermelhado/ruivo, entrelaçadas, entwining. E nesse ponto, introduz novos versos citados, de Dante, dando-nos a impressão desses dois-a-dois, três-a-três referirem-se à métrica a andantes, homens, dois, prostitutas, três, associando sexo a inferno.

...per l'era perso, através desse obscuro elemento de malva, de púrpura, quella pacifica oriafiamma, tão ardente a pacífica chama, de ouro de auriflama, di riminar fe piu ardenti, fez meus olhos mais perspicazes para ver.

Mas eu, homens velhos, penitentes, pés-de-chumbo, adentrando a noite: boca sul: tomb womb.

Chegando a tomb womb infere-se ser boca sul alusão ao útero, ao ventre, com todo o peso da expressão tomb, túmulo, sepultura, tumba. Então, a boca (ao) sul refere-se à origem-fim da vida: o útero tumular, mas mantendo a possibilidade de tumba - tomb - acolhedora $-w o m b-$. 
Nenhuma dessas imagens torna-se perceptível na tradução de Houaiss, na qual, por exemplo tomb womb passa a ser entre ventre, não querendo dizer muita coisa. Sua preocupação foi a de manter a rima, a métrica marcada pelas silabas.

Frisemos um aspecto: as obscenidades no texto seguem a origem latina etimológica da palavra obscena: colocar em cena, mas sob a forma velada de alusões, referências a uma aparente exibição de detalhes minuciosos recriados por tropos de linguagem. Mas justamente nesses momentos o nosso tradutor parece amenizar alguns termos, fazendo uso de certos preciosismos da língua portuguesa que não correspondem necessariamente à intenção do autor, o qual faz uso de termos correntes no linguajar mais corriqueiro. Talvez um possível excesso de pudicidade por parte de nosso tradutor justifique o evitar correspondências alusivas ao que poderia parecer-lhe questionável idealmente.

Finalizando essas considerações, diremos, ao ler Joyce, aprender algo que, parece-nos, também Lacan aprendeu lendo-o: o gozo nas letras. E em nosso auxílio concorre Borges, ao afirmar: Quando pensamos nas palavras, pensamos historicamente que no princípio as palavras foram som e que depois chegaram a ser letras. Ao invés disso, na cabala (que quer dizer recepção, tradição) supõese que as letras são anteriores; que as letras foram os instrumentos de Deus, e não as palavras representadas pelas letras. É como pensar que a escrita, contrariando toda a experiência, foi anterior à dicção das palavras. Nesse caso, nada é casual na Escritura: tudo tem de ser determinado. Por exemplo, o número das letras de cada versículo. Essas palavras de Borges, em A Cabala, indicam-nos uma nova possibilidade de leitura de Lacan a partir de Joyce, inclusive a partir da própria propriedade magnetizável da letra, sobretudo em nomes próprios. Isso significa afirmar, na clínica, haver transferência literal à letra antes que ao som das palavras produzido pelo significante que utiliza as letras para a composição de palavras. 